\begin{tabular}{l} 
Final Report Certification \\
for \\
CRADA Number $\quad$ ORNL 02-0658 \\
\hline
\end{tabular}

Between

UT-Battelle, LLC

and

Caterpilar, Ince

(Participant)

Instructions:

Mark the appropriate statement in 1a or 1b below with an "IX." Refer to the articles in the CRADA terms and conditions governing the identification and marking of Protected CRADA Information (PCl).

If no $\mathrm{PCl}$ is identified, the report will be distributed without restriction. If $\mathrm{PCl}$ is identified, the report distribution will be limited in accordance with the CRADA terms and conditions governing release of data. In all cases items 2 and 3 must be true. That is, the report cannot contain Proprietary Information and a disclosure must be filed prior to release of the report.

This certification may either be made by using this form or may be made on company letterhead if the Participant desires. A faxed copy of this completed form is acceptable.

The following certification is made for the subject final report:

1. (a) $\square$ The final report contains information that qualifies as "Protected CRADA information" (PCI). The PCl legend is printed on the report cover, and the $\mathrm{PCl}$ is clearly identified.

OR

(b) $\triangle$ The final report does not contain "Protected CRADA Information." The "Approved for Public Release" legend is printed on the report cover.

2. The final report does not contain Proprietary Information.

3. By the signature below, the Participant has no objection to the public distribution of the final report due to patentable information.
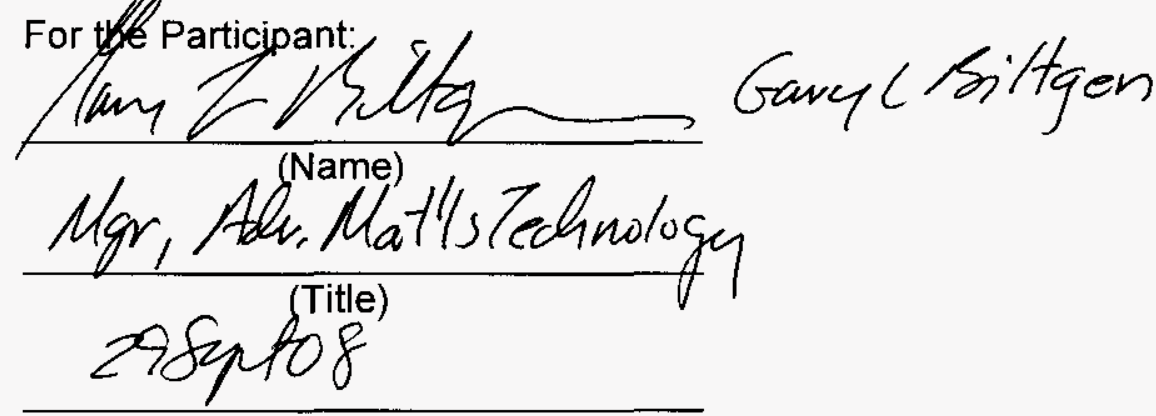

(Date) 
C/ORNL02-0658

Materials Science and Technology Division

CRADA Final Report

For

CRADA Number ORNL02-0658

Advanced Cast Austenitic Stainless Steels for High Temperature Components

P. J. Maziasz, J.P. Shingledecker and

N.D. Evans

Oak Ridge National Laboratory

M. J. Pollard, Caterpillar, Inc.

Prepared by

Oak Ridge National Laboratory

Oak Ridge, TN 37831

Managed by

UT-Battelle, LLC

For the

U.S. Department of Energy

Under contract DE-AC05-00OR22725

Approved for Public Release

Unlimited Distribution 
C/ORNL02-0658

Materials Science and Technology Division

CRADA Final Report

For

CRADA Number ORNL02-0658

Advanced Cast Austenitic Stainless Steels for High Temperature Components

P. J. Maziasz, J.P. Shingledecker, and N.D. Evans

Oak Ridge National Laboratory

\author{
M. J. Pollard \\ Caterpillar, Inc. \\ Prepared by \\ Oak Ridge National Laboratory \\ Oak Ridge, TN 37831 \\ Managed by \\ UT-Battelle, LLC \\ For the \\ U.S. Department of Energy \\ Under contract DE-AC05-00OR22725 \\ Approved for Public Release \\ Unlimited Distribution
}

Research was supported through a CRADA with Caterpillar, Inc., sponsored by the U.S. Department of Energy, Assistant Secretary for Energy Efficiency and Renewable Energy, Office of Vehicle Technologies, as part of the Propulsion Materials Program, under contract DE-AC05-00OR22725 with UT-Battelle, LLC. 


\title{
ADVANCED AUSTENITIC STAINLESS STEELS FOR HIGH TEMPERATURE COMPONENTS
}

\author{
CRADA No. ORNL02-0658 \\ between \\ Oak Ridge National Laboratory \\ and \\ Caterpillar, Inc.
}

\begin{abstract}
In July of 2002, a Cooperative Research and Development Agreement (CRADA) was undertaken between Oak Ridge National Laboratory (ORNL) and Caterpillar, Inc. (Caterpillar Technical Center) to develop and commercialize new cast stainless steels invented and initially tested on a prior CRADA. This CRADA is a direct follow-on project to CRADA ORNL-990533 for diesel engine exhaust component and gas turbine engine structural component applications. The goal of this new CRADA was to develop and commercialize the newly discovered cast stainless steels (primarily CF8C-Plus) with improved performance and reliability, as lower-cost upgrade alternatives to more costly cast Ni-based superalloys.
\end{abstract}

\section{Background}

The advanced diesel engine components considered for truck applications $(\mathrm{C} 10, \mathrm{C} 12,3300$ and 3400) were the exhaust manifold and turbocharger housing made from commercial high SiMo ductile cast iron with uses limited to $700-750^{\circ} \mathrm{C}$ or below. The gas-turbine structural components considered for the Mercury-50 engine were the combustor housing and end-cover, and the center-frame hot-plate, both made from commercial CF8C cast austenitic stainless steel (Fe$19 \mathrm{Cr}-12 \mathrm{Ni}-\mathrm{Nb}, \mathrm{C})$, which is generally limited to use at below $650^{\circ} \mathrm{C}$.

The prior CRADA, ORNL99-0533, initially emphasized both gas-turbine materials (347H and CF8C stainless steels), but ended with the emphasis primarily on diesel engine materials (SiMo cast-iron and CN-12 stainless steel). For the diesel applications in this CRADA, commercial SiMo cast iron and standard cast CN12 austenitic stainless steel (Fe-25Cr-13Ni-Nb,C,N,S) were baseline materials because they were commercially available. CRADA ORNL99-0533 showed that for tensile and creep testing from room temperature to $900^{\circ} \mathrm{C}$, the $\mathrm{CN} 12$ cast austenitic stainless steel had far superior strength compared to $\mathrm{SiMo}$ cast iron above $550^{\circ} \mathrm{C}$, together with outstanding oxidation resistance. However, aging at $850^{\circ} \mathrm{C}$ reduced room-temperature ductility of the standard $\mathrm{CN} 12$, and creep-rupture resistance at $850^{\circ} \mathrm{C}$ was less than expected, which prompted the laboratory-scale alloy development effort on modified cast austenitic stainless steels at ORNL toward the end of the first CRADA. Isothermal fatigue testing at $700^{\circ} \mathrm{C}$ also showed that standard $\mathrm{CN} 12$ was far superior to SiMo cast iron, but the fatigue data were inconsistent due to premature, brittle fracture, so a cast austenitic stainless steel with better fatigue resistance at $700-800^{\circ} \mathrm{C}$ was needed. 
CRADA ORNL02-0658 began with two new modified cast stainless steels developed during the first CRADA, a modified CF8C (CF8C-Plus) steel, and a modified CN12 (CN12-Plus) steel. Both new alloy compositions were based on compositional changes specifically designed to change the nature, dispersion and stability of the as-cast and high-temperature aging-induced microstructures that consisted of carbides and other precipitate phases. The new CF8C-Plus steel showed tensile and creep-rupture strength comparable to standard $\mathrm{CN} 12$ steel at $850^{\circ} \mathrm{C}$, due to a unique and very stable microstructure. Based on very successful initial data on the ORNL lab-scale heats, the new CRADA ORNL02-0658 began with commercial scale-up, testing and evaluation of CF8C-Plus and CN12-Plus, and a goal to down-select the best cast stainless steel for making trial/prototype exhaust components after about two years.

\section{Objectives}

The objective of this CRADA was to the evaluate commercial scale-up, high-temperature properties and relative benefits of the new CF8C-Plus and CN12-Plus cast austenitic stainless steels as high-performance upgrades to SiMo ductile cast iron, which was the standard material used for most diesel engine exhaust manifolds and turbocharger housings. The cast austenitic stainless steel upgrade material must withstand prolonged exposure at temperatures of $750^{\circ} \mathrm{C}$ or above, and reliably endure the severe thermal cycling from near room-temperature to such hightemperatures without cracking. The initial goal of this CRADA was to select the most costeffective austenitic upgrade material for further commercial scale-up. Additional ORNL lab-scale alloy modifications for improved high-temperature performance would also be considered, in parallel with the commercial-scale evaluation. At Caterpillar, the new CF8C-Plus cast stainless steel was evaluated for both the Solar Turbines gas-turbine application, as well as the C-15 heavy-duty on-highway diesel engine application, but at ORNL, the primary emphasis was on the diesel engine exhaust components application.

\section{Benefits to DOE Mission}

This program directly benefited the DOE/EERE OTT HVPM program by developing both the new and improved CF8C-Plus and CN12-Plus cast austenitic stainless steels, which can withstand higher diesel engine temperatures, and enable both better fuel efficiency and lower emissions. These new alloys also overcome the barrier of reduced lifetime at higher operating temperatures, because normally increased temperature and increased lifetime are trade-offs. Scientific and rapid alloy design provided the CF8C-Plus steel with both improved temperature capability, as well as improved durability and reliability. This outstanding achievement was recognized by CF8C-Plus steel winning the $2003 \mathrm{R} \& D 100$ Award. An additional benefit is that in 2007, CF8C-Plus steel was commercially deployed as the Caterpillar Regeneration System (CRS) burner units necessary to regenerate the ceramic diesel particulate filters (DPF) required on all on-highway diesel engines after January, 2007. To date, more than 400 tons of CF8C-Plus has been cast for this CRS application. U.S. Patents were obtained for both the CF8C-Plus and CN12-Plus steels, and an additional U.S. Patent application was filed to capture the benefits of the CF8C-Plus $\mathrm{Cu} / \mathrm{W}$ steel, so an additional benefit to DOE is an enormous technology transfer effort for CF8C-Plus cast steel, that began in 2007 for turbocharger housings (truck and automotive), and land-based gas-turbine casings and critical internal components; these new commercialization opportunities will likely continue and expand. 


\section{Technical Discussion of Work Performed}

The original work-scope for this three-year CRADA had three main tasks. The first task was to obtain commercial castings of both CF8C-Plus and CN12-Plus steels, and the second task was to measure creep, fatigue and oxidation properties of both new modified cast steels. The third task was to evaluate prototype diesel exhaust components of both new cast steels, and the fourth task was to compare these new cast stainless steels to other commercial heat-resistant alloys to determine their relative improvements in performance and market potential for other applications. During the first task, the advantages of the CF8C-Plus steel for diesel exhaust components became apparent, and were validated when CF8C-Plus steel development won a 2003 R\&D100 Award. The good castability and excellent initial high-temperature mechanical properties data accelerated various different commercial component trials, which then led to extension of this CRADA for four additional years. The final three years involved additional alloy development of the CF8C-Plus $\mathrm{Cu} / \mathrm{W}$ steel with improved strength and creep-resistance relative to $\mathrm{CF} 8 \mathrm{C}$-Plus steel at $750^{\circ} \mathrm{C}$ and above. The final two years included additional testing to support thin-section castings for exhaust component applications, and ORNL and Caterpillar applied for a new ASTM alloy grade (HG10MNN) for the CF8C-Plus steel.

\section{Commercial Scale-Up of CF8C-Plus Steel}

This CRADA began with the $850^{\circ} \mathrm{C} / 35 \mathrm{MPa}$ creep-test of the first CF8C-Plus steel specimen from the first ORNL lab-scale heat approaching 20,000h (Fig. 1). That test result, and several other factors at Caterpillar resulted in the decision to commercially scale-up the CF8C-Plus steel and compare it to standard CF8C steel (used for gas-turbine casing by Solar Turbines, Inc., a Caterpillar Company) and standard CN12 steel (investigated previous for exhaust manifold applications jointly by a Caterpillar, Ford Motor Company and General Motors). In 2002, MetalTek International made $500 \mathrm{lb}$ heats of CF8C and CF8C-Plus, while Wollaston made 500 $\mathrm{lb}$ heats of $\mathrm{CN} 12$ and CF8C-Plus. Both produced kiel-block ingots cast in sand to make tensile/creep and fatigue specimens for mechanical properties testing. MetalTek also poured Chinese-script patterns to measure metal-fluidity, and found the CF8C-Plus steel (with added Mn and N) to have much better fluidity than the standard CF8C steel. Prior ORNL screening tests of CF8C-Plus steel showed that tensile and creep-strength had better properties in the as-cast condition, with no additional heat-treatments after casting, so the standard CF8C steel was also tested in the as-cast condition (typical processing could include a solution-anneal of $1 \mathrm{~h}$ at $1050^{\circ} \mathrm{C}$ ). In 2003-2004, Caterpillar obtained another heat of CF8C-Plus for additional fatigue testing. Commercial scale-up of CF8C-Plus steel occurred about 1.5 years after the first (and only) lab-scale heat was made at ORNL.

\section{High-Temperature Mechanical Properties Evaluation of CF8C-Plus Steel}

Commercial cast CN12 austenitic stainless steel has much more C and N than CF8C-Plus (0.45 compared to $0.1 \% \mathrm{C}$, and 0.4 compared to about $0.25 \% \mathrm{~N}$, respectively). However, tensile testing from room to $900^{\circ} \mathrm{C}$ showed that as-cast CF8C-Plus had similar strength and much more ductility than $\mathrm{CN} 12$ over the entire temperature range (Fig. 2). CF8C-Plus steel was also about 1.5 times stronger, but just as ductile, as the standard CF8C steel. The combination of good strength and ductility was considered very important for the fatigue and thermal-fatigue resistance needed for various thin-walled stainless steel diesel exhaust components. Creep- 
rupture data for tests at $650-800^{\circ} \mathrm{C}$ showed that CF8C-Plus steel had about twice the creeprupture strength of standard $\mathrm{CF} 8 \mathrm{C}$ steel, orders of magnitude more creep-strength than Ni-resist austenitic cast-iron or SiMo cast-iron (Fig. 3a). These results validated the interest in CF8C-Plus steel for several different diesel exhaust component applications. Cast CF8C-Plus steel has as much or more creep-rupture strength than a range of wrought commercial heat-resistant austenitic stainless steels and alloys, including NF709, which was recently included in the ASME code for coal-fired steam boiler tubing (Fig. 3b). The creep strength of CF8C-Plus steel comes close to that of the solid-solution strengthened Ni-based superalloy 617 , which is about 5-7 times more costly. This comparison indicated that CF8C-Plus steel had the potential to be used in a range of other applications, including gas-turbine casings and components.

Isothermal low-cycle fatigue (LCF) testing in air was conducted by Caterpillar, comparing standard CF8C steel with the new CF8C-Plus steel in the as-cast condition at $700-800^{\circ} \mathrm{C}$. Generally, CF8C-Plus steel showed more fatigue resistance than the standard CF8C steel, because it was able to achieve endure-limits at higher values of strain damage (Fig. 4). Caterpillar also conducted selective in-phase and out-of-phase (more damaging) thermomechanical fatigue (TMF) testing of CF8C-Plus, and data showing the large advantage in TMF resistance relative to SiMo cast-iron are shown in Fig. 5.

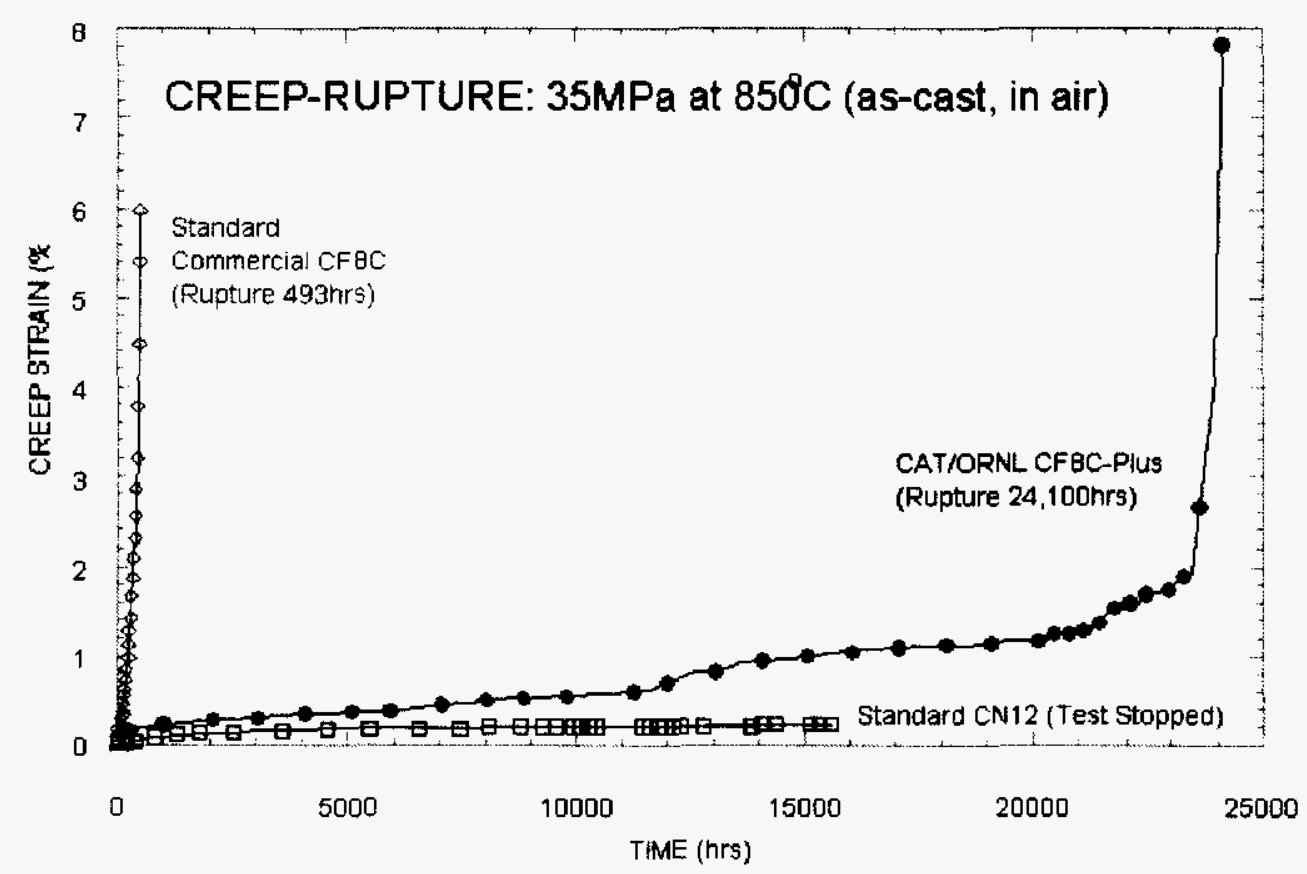

Fig. 1 - Plot of creep strain versus time for the first specimen of as-cast CF8C-Plus steel (from the first lab-scale heat cast at ORNL), tested in air at $850^{\circ} \mathrm{C}$ and $35 \mathrm{MPa}$. Similar ORNL creeptest data are included for specimens from commercial heats of standard CF8C and CN12 steels. The standard CN12 steel test was stopped without rupture. 

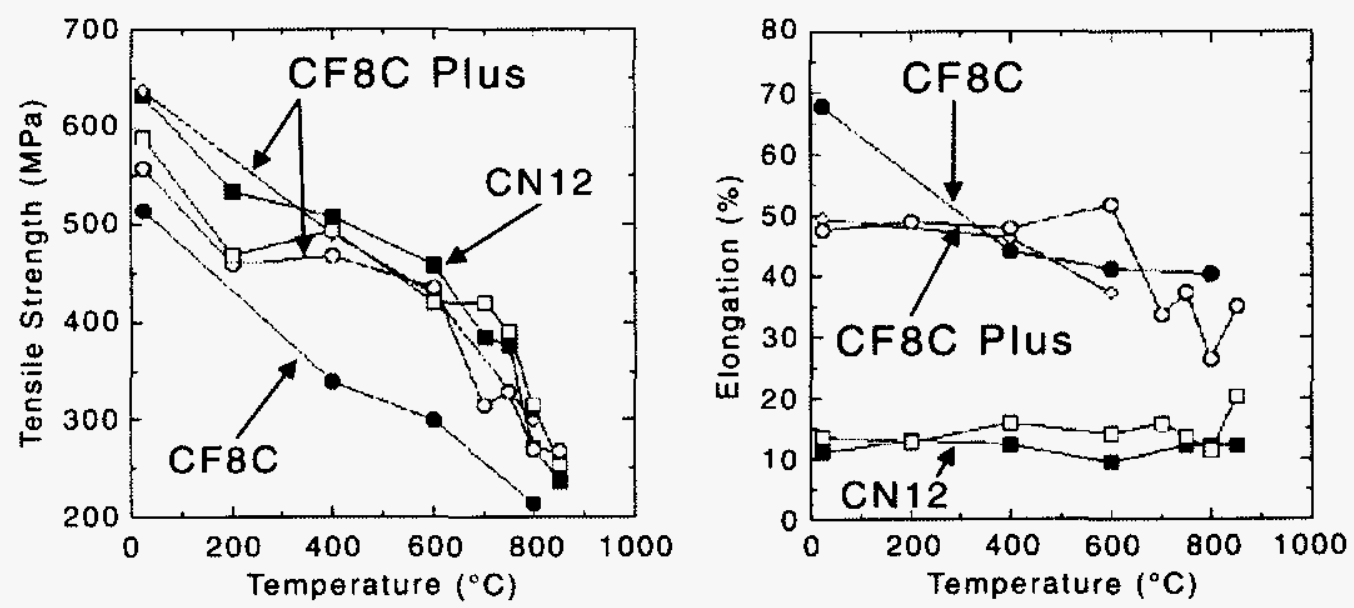

Fig. 2 - Plots of ultimate tensile strength (UTS) and total elongation (TE) as functions of test temperature for the first commercially cast heats of the new CF8C-Plus steel, and for standard heats of CF8C and CN12 steels cast for comparison.

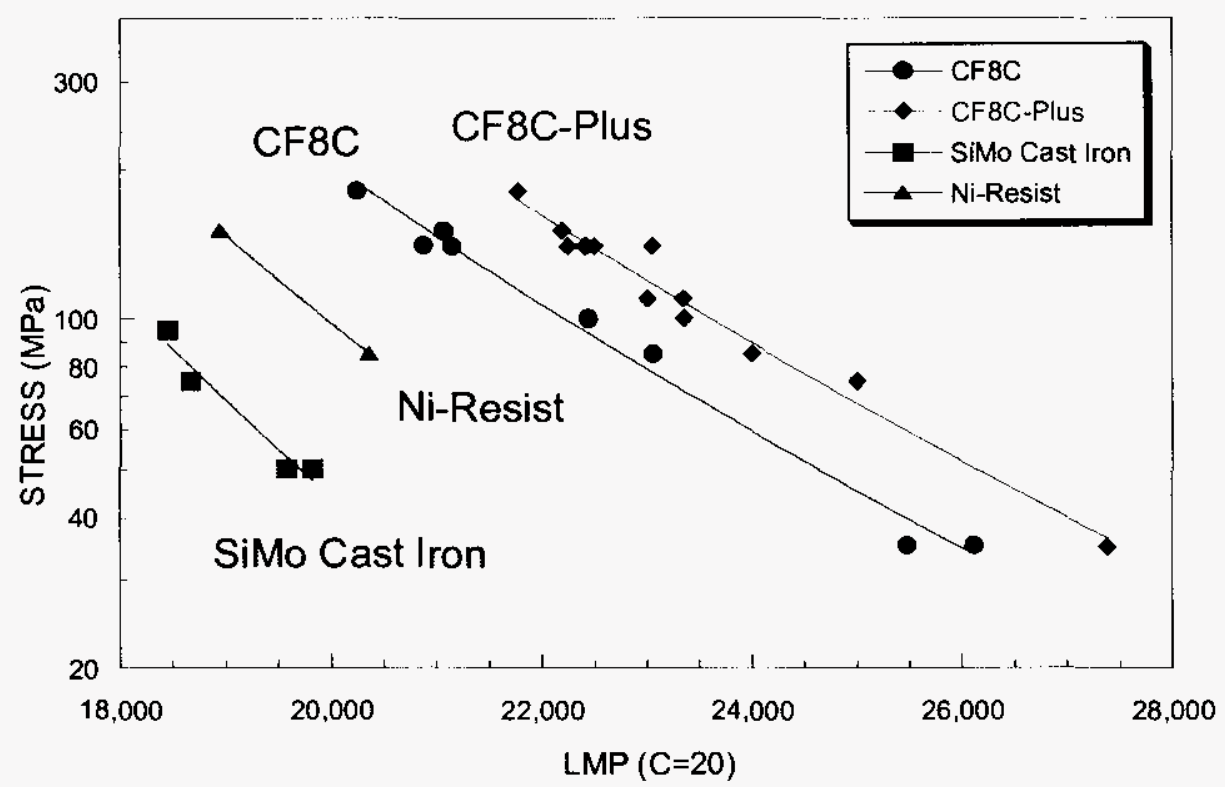

A 


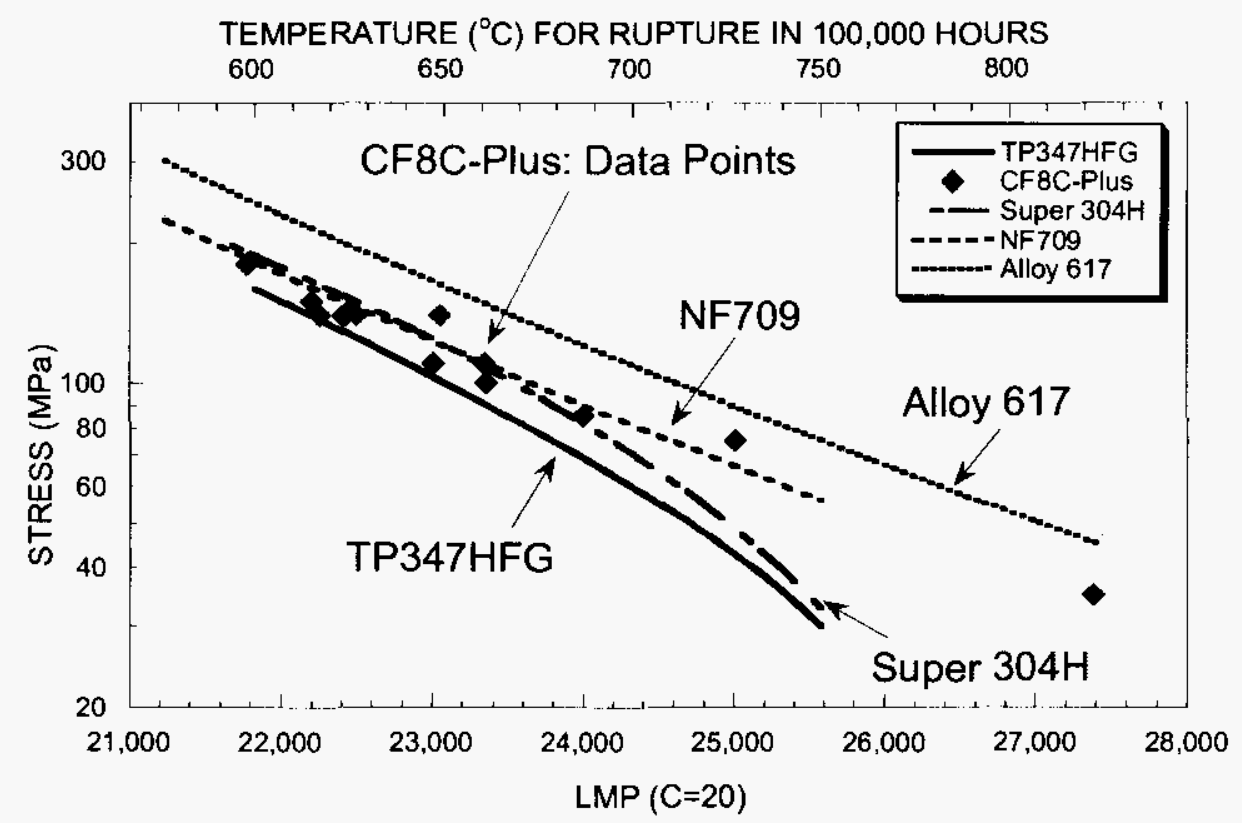

B

Fig. 3 Creep-rupture strength plotted versus Larson-Miller Parameter (calculated using test temperature and rupture-life) for CF8C-Plus steel compared to a) the standard CF8C steel and SiMo and Ni-resist cast-irons used for many diesel engine exhaust components, and b) the typical wrought heat-resistant austenitic stainless steels and alloys used in fossil-power generation, including the Ni-based superalloy 617 .

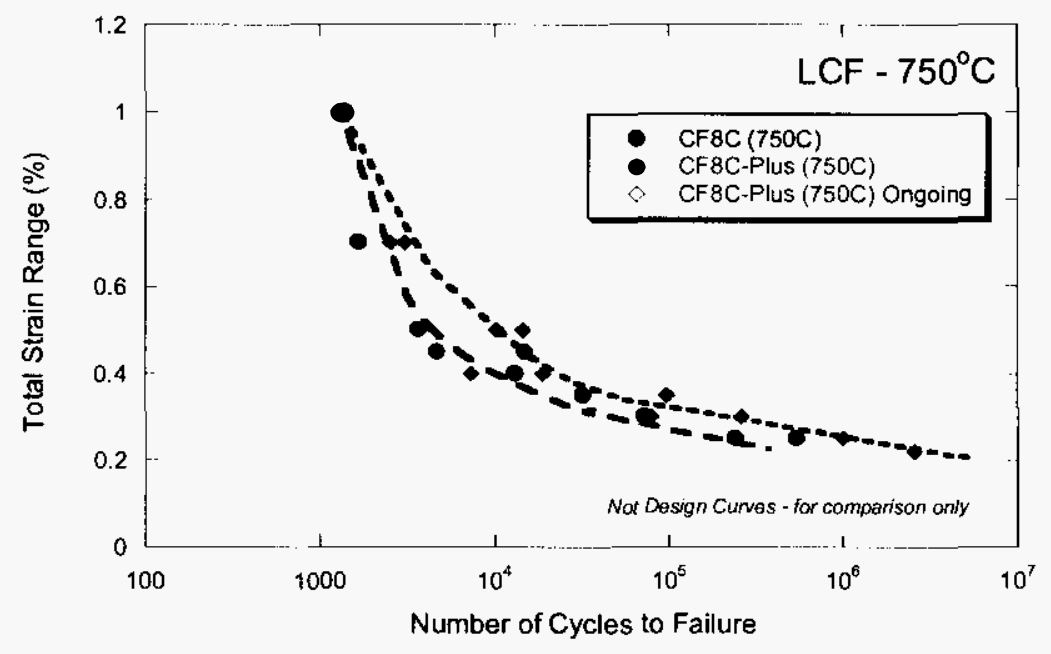

$\mathbf{A}$ 


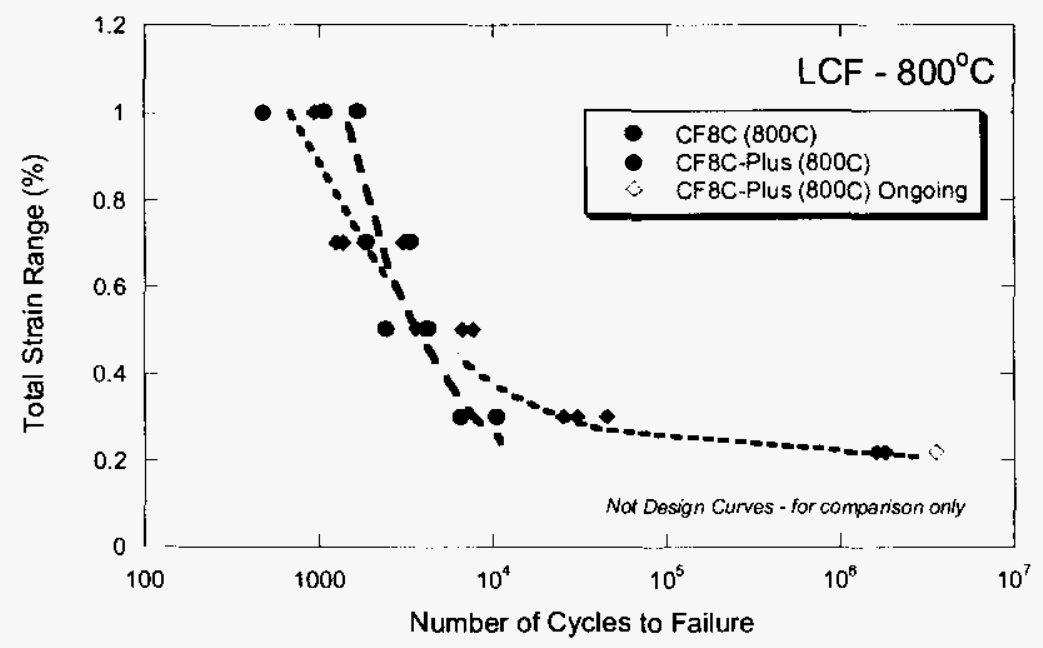

B

Fig. 4 - Isothermal low-cycle fatigue (LCF) testing of as-cast standard CF8C and the new CF8C-Plus steels in air at a) $750^{\circ} \mathrm{C}$, and b) $800^{\circ} \mathrm{C}$. CF8C-Plus shows better fatigue resistance because it achieves an endurance-limit at higher strain values.

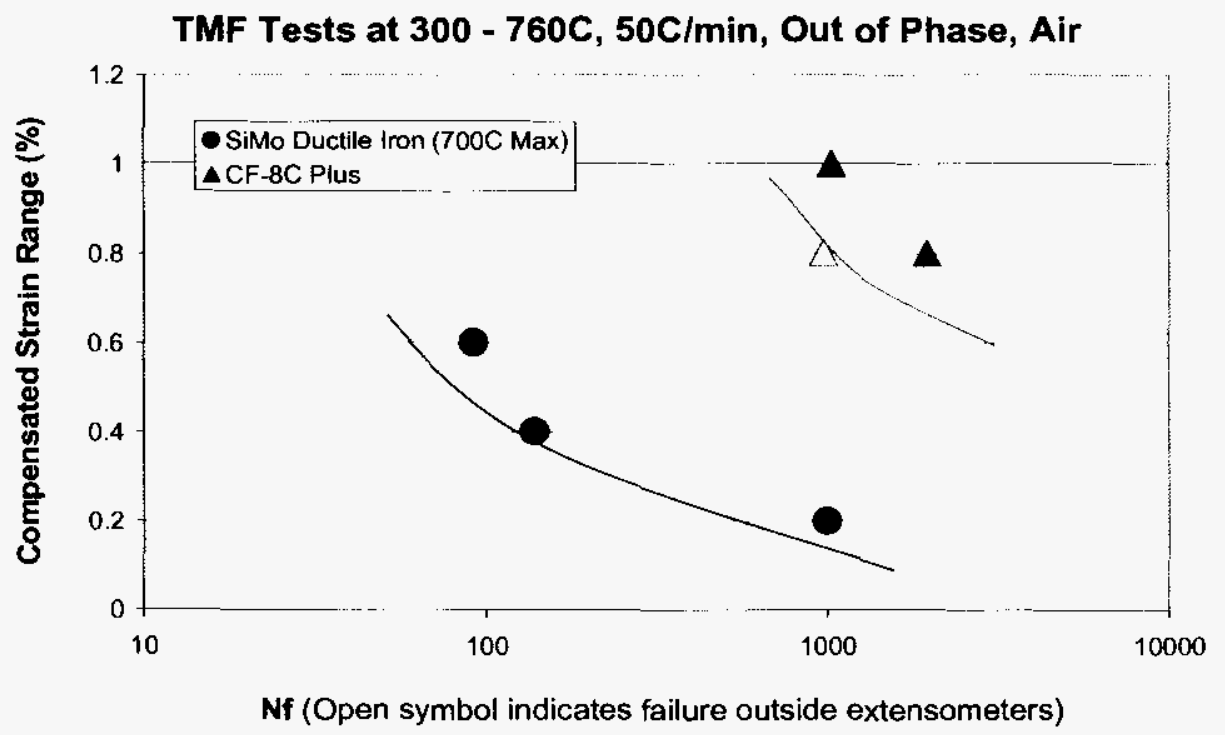

Fig. 5 - Out-of-phase thermomechanical fatigue (TMF) testing (at Caterpillar) in air, with a thermal cycle ranging from $300-760^{\circ} \mathrm{C}$ for $\mathrm{CF} 8 \mathrm{C}$-Plus cast stainless steel, but a $300-700^{\circ} \mathrm{C}$ thermal cycle for SiMo cast iron. A relatively slower heating/cooling rate of $50^{\circ} \mathrm{C} / \mathrm{min}$ was 
used for both alloys. CF8C-Plus steel has significantly more TMF resistance than SiMo cast iron, despite being subjected to a higher maximum cycle temperature.

Caterpillar and ORNL also conducted some aging studies out to $10,000 \mathrm{~h}$ at $600-800^{\circ} \mathrm{C}$, Charpyimpact testing, and selected creep-fatigue testing, but those data are not included here. Any additional data may be available by directly contacting Caterpillar, particularly for testing and licensing interest in CF8C-Plus for other applications.

\section{Further Commercial Scale-Up and Component Trials for CF8C-Plus Steel}

The good initial properties data on CF8C-Plus steel, including excellent as-cast strength, ductility and creep-resistance, combined with very good metal fluidity, prompted a range of initial cast component trials in 2004-2006. One outstanding example of first-time prototype casting success was production of a $6,700 \mathrm{lb}$ CF8C-Plus turbine casing ( $8000 \mathrm{lb}$ initial heat) by MetalTek International in 2005, using centrifugal casting methods (Fig. 6). The component was an endcover for the Solar Turbines Mercury 50 industrial gas turbine engine (4.6MW, low NOx), with a flange to connect to the recuperator. The component had no surface cracking or defects, and sectioning for inspection and specimens for properties measurements showed a sound component, free of any internal cracks or defects.

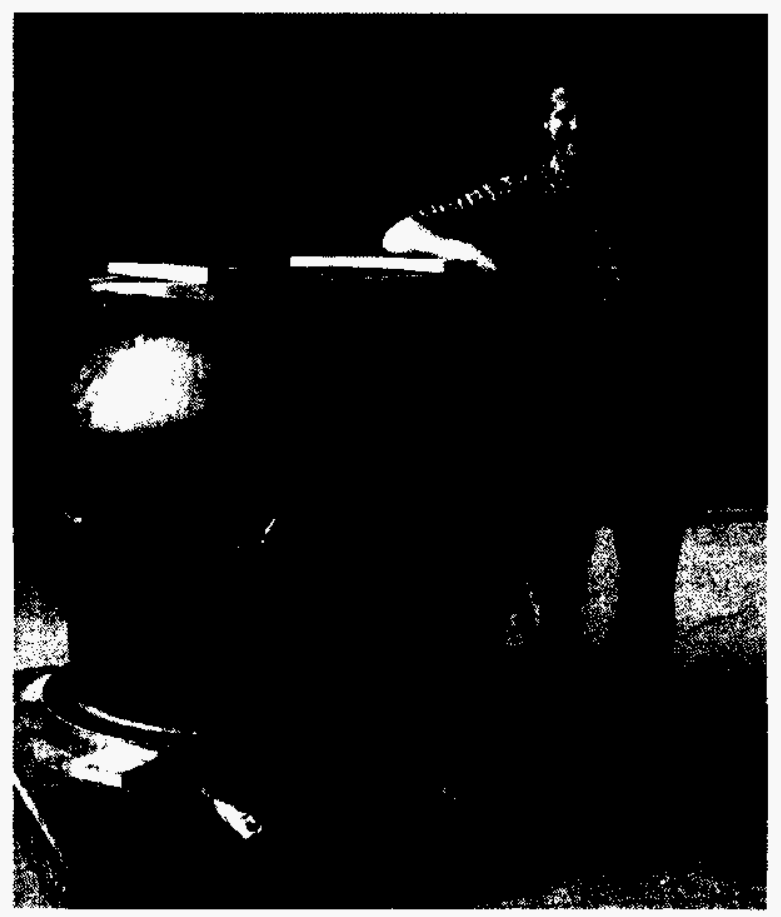

Fig. 6 - CF8C-Plus steel casting $(6,700 \mathrm{lb})$ of an end-cover for the Solar Turbines Mercury 50 gas-turbine engine, produced by centrifugal casting methods by MetalTek International in 2005. Pictured is Mike Pollard at the Caterpillar Technical Center. 


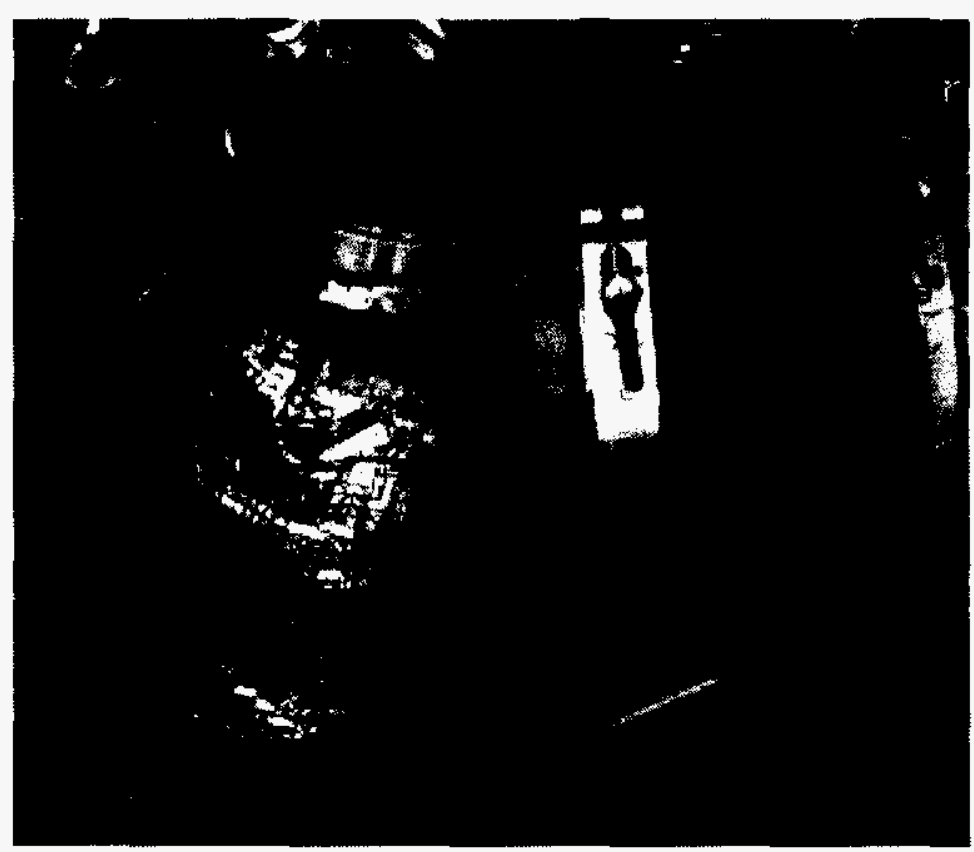

Caterpillar Regeneration System (CRS) Housing

A

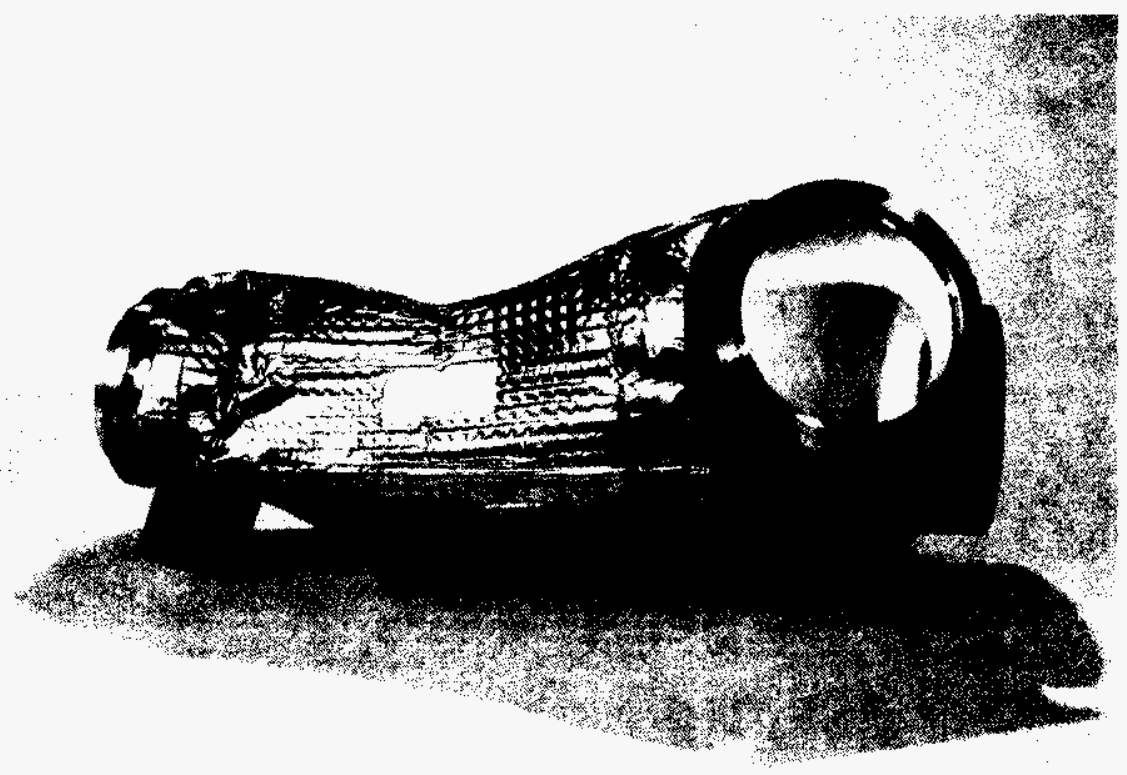

B

Fig. 7 - Pictures of a) a CF8C-Plus cast austenitic stainless steel CRS unit adjacent to the turbocharger on a diesel engine, and b) a fresh CRS unit by itself, showing the heat-shield needed to protect other engine-components. Diesel fuel is injected into the exhaust from the turbocharger to begin the combustion process that removes particles clogging the DPF. The CRS unit is subject to very high temperatures and rapid thermal cycling. 
In 2006, Caterpillar began the testing needed to qualify the new CF8C-Plus cast stainless steel for a demanding exhaust component application as the burner housing attached to the turbocharger (Fig. 7), to clean and regenerate the ceramic diesel particulate filter (DPF). The Caterpillar Regeneration System (CRS) and DPF were required for all on-highway truck diesel engines, due to new EPA restrictions on diesel emissions that took effect in January, 2007. To date, over 300 tons of CF8C-Plus stainless steel have been cast for this first commercial application, and none of these parts have failed. Successful deployment of the CRS units is now driving interest in upgrading the turbocharger housing from SiMo cast-iron to CF8C-Plus steel as well.

\section{Development and Commercial Scale-Up of CF8C-Plus $\mathrm{Cu} / \mathrm{W}$ Steel}

The CF8C-Plus cast stainless steel was designed specifically to have $\mathrm{Mn}$ and $\mathrm{N}$ added to stabilize the austenite parent phase against delta-ferrite formation during casting, and to resist the formation of embrittling intermetallic phases, like Cr-rich sigma phase during long-term aging. The $\mathrm{Mn}$ was added to enhance the alloy strength and work-hardening characteristics, and to increase the solubility of the austenite matrix for N. High-temperature strength during aging or creep was due to the formation of nano-scale dispersions of $\mathrm{NbC}$, and (as confirmed recently) $\mathrm{Nb}$-rich nitrides. While standard $\mathrm{CF} 8 \mathrm{C}$-Plus has $15-25 \%$ delta-ferrite, the as-cast CF8C-Plus has none. The delta-ferrite was observed to rapidly convert to sigma-phase during aging at $700-800^{\circ} \mathrm{C}$, but similar or longer aging of CF8C-Plus produce no sigma-phase. Sigma phase was not observed even after creep at $850^{\circ} \mathrm{C} / 35 \mathrm{MPa}$ for $24,000 \mathrm{~h}$.

In 2005, alloy modifications of $\mathrm{B}, \mathrm{Al}, \mathrm{Cu}$ and $\mathrm{W}$ were made as lab-scale heats at ORNL, and tested to see if they would improve the strength and creep-resistance of CF8C-Plus at $750^{\circ} \mathrm{C}$ and above. The alloying additions of $\mathrm{Cu}$ and $\mathrm{W}$ were found to be most beneficial, so a series of commercial centrifugal castings of $\mathrm{CF} 8 \mathrm{C}$, CF8C-Plus and $\mathrm{CF} 8 \mathrm{C}-\mathrm{Plus} \mathrm{Cu} / \mathrm{W}$ were made at MetalTek-International. Creep-rupture testing of specimens from these casting showed a definite boost in creep-strength and rupture-resistance of the CF8C-Plus $\mathrm{Cu} / \mathrm{W}$ at 750 and $850^{\circ} \mathrm{C}$ (Fig. 8). The CF8C-Plus steel has considerably higher creep-rupture ductility than the standard CF8C steel (Fig. 9), despite also being much stronger, mainly due to the lack of deltaferrite in the as-cast structure, and the lack of sigma-phase formation during long-term creep. The creep-rupture ductility of the CF8C-Plus $\mathrm{Cu} / \mathrm{W}$ is lower than that of the CF8C-Plus steel, but still remains in the $10-40 \%$ range, and the reduction in creep ductility is probably due to the increase in creep-strength. Later in 2006, step-castings of both CF8C-Plus and CF8C-Plus $\mathrm{Cu} / \mathrm{W}$ were cast at Stainless Foundry \& Engineering (SF\&E) to test the effects of thinner cast sections on microstructure and properties, in anticipation of using either of these steels for thinwalled exhaust component applications, including turbocharger housings and exhaust manifolds. Each ingot had steps that were 1, 0.5 and 0.25 inches thick, and the initial tensile and creep-rupture testing confirmed similar or better mechanical properties of the thinnest sections relative to thicker static sand-castings, or the much thicker centrifugal castings. This CRADA project ends in July, 2008 with the three long-term creep-rupture tests of CF8C-Plus and $\mathrm{CF} 8 \mathrm{C}$-Plus $\mathrm{Cu} / \mathrm{W}$ continuing at $750^{\circ} \mathrm{C}$, as shown in Fig. 10 . Several of those tests are approaching $30,000 \mathrm{~h}$. At similar or higher stresses, the CF8C-Plus $\mathrm{Cu} / \mathrm{W}$ exhibits less primary creep, and a very low creep-rate in the secondary creep regime that should be beneficial for both diesel turbocharger and exhaust manifold applications. 


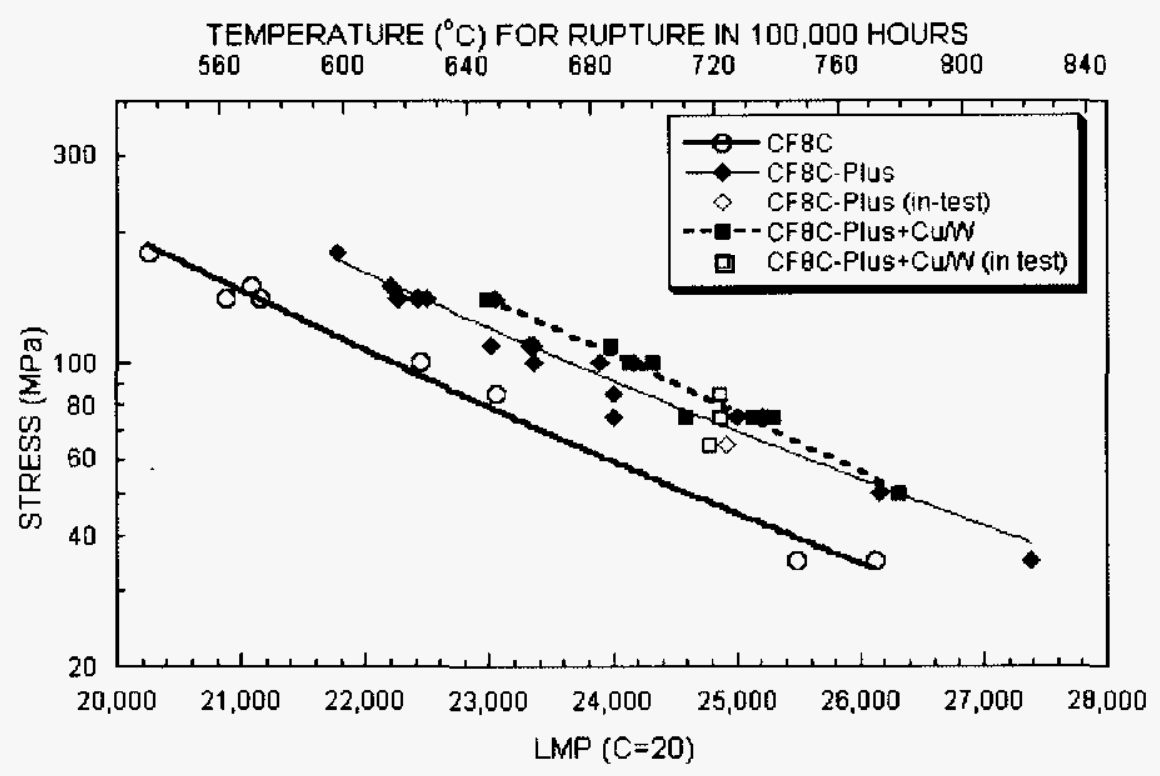

Fig. 8 - Larson-Miller Parameter (LMP) comparisons between CF8C-Plus steel, CF8C-Plus $\mathrm{Cu} / \mathrm{W}$ steel and standard $\mathrm{CF} 8 \mathrm{C}$ steel. The top abscissa gives the estimated temperature $\left({ }^{\circ} \mathrm{C}\right)$ for rupture in 100,000 hours. The creep strength of CF8C-Plus steel is much better than that of standard $\mathrm{CF} 8 \mathrm{C}$ steel, and the $\mathrm{CF} 8 \mathrm{C}-\mathrm{Plus} \mathrm{Cu} / \mathrm{W}$ shows a strength boost relative to the CF8CPlus steel. Most data come from static-cast kiel blocks or centrifugally-cast rings, but these data also include recent tests on thinner sections in step-cast ingots.

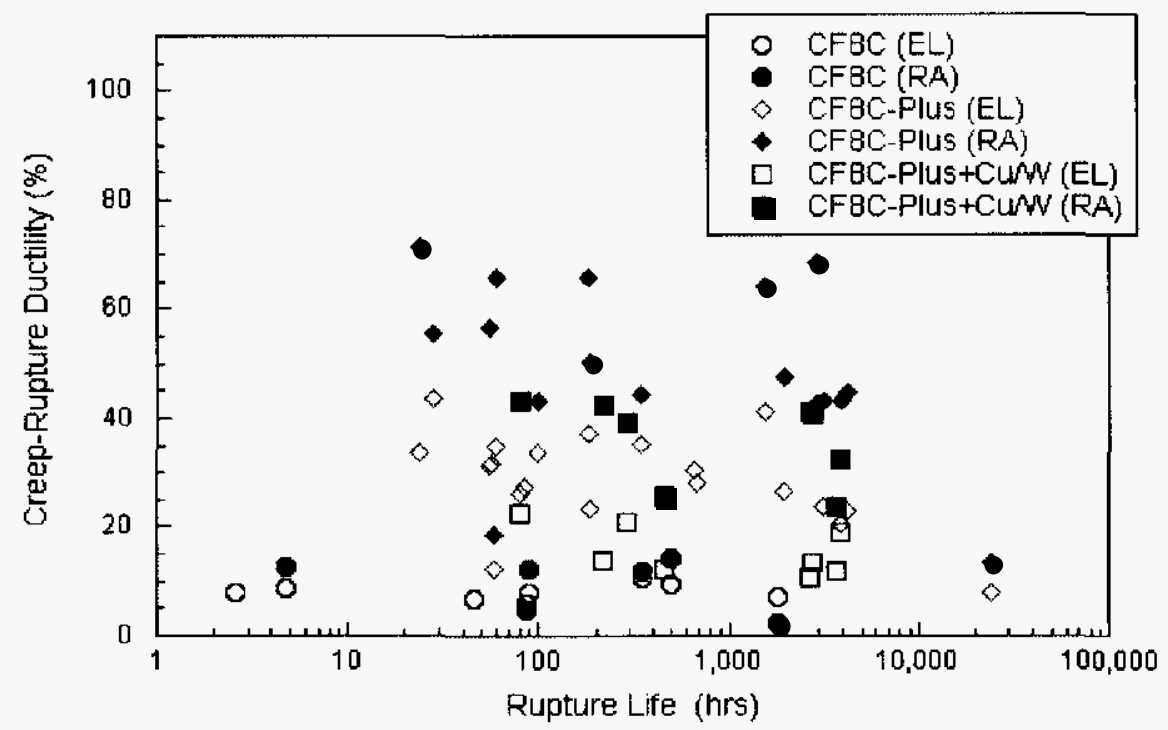

Fig. 9 - Rupture Elongation vs. Time for $\mathrm{CF} 8 \mathrm{C}, \mathrm{CF} 8 \mathrm{C}$-Plus and $\mathrm{CF} 8 \mathrm{C}-\mathrm{Plus} \mathrm{Cu} / \mathrm{W}$ steels, all creep-tested between 650 and $850^{\circ} \mathrm{C}$ at 35 to $200 \mathrm{MPa}$. CF8C-Plus and CF8C-Plus $\mathrm{Cu} / \mathrm{W}$ do not form embrittling grain boundary phases during creep, resulting in excellent rupture ductility compared to that of CF8C steel, which initially contains $15-25 \%$ delta-ferrite that transforms to sigma phase at elevated temperatures. Test data in this figure correspond to the same creep- 
tested specimens used to generate the data in Fig. 8. In the legend, EL stands for total elongation, and RA stands for reduction-in-area.

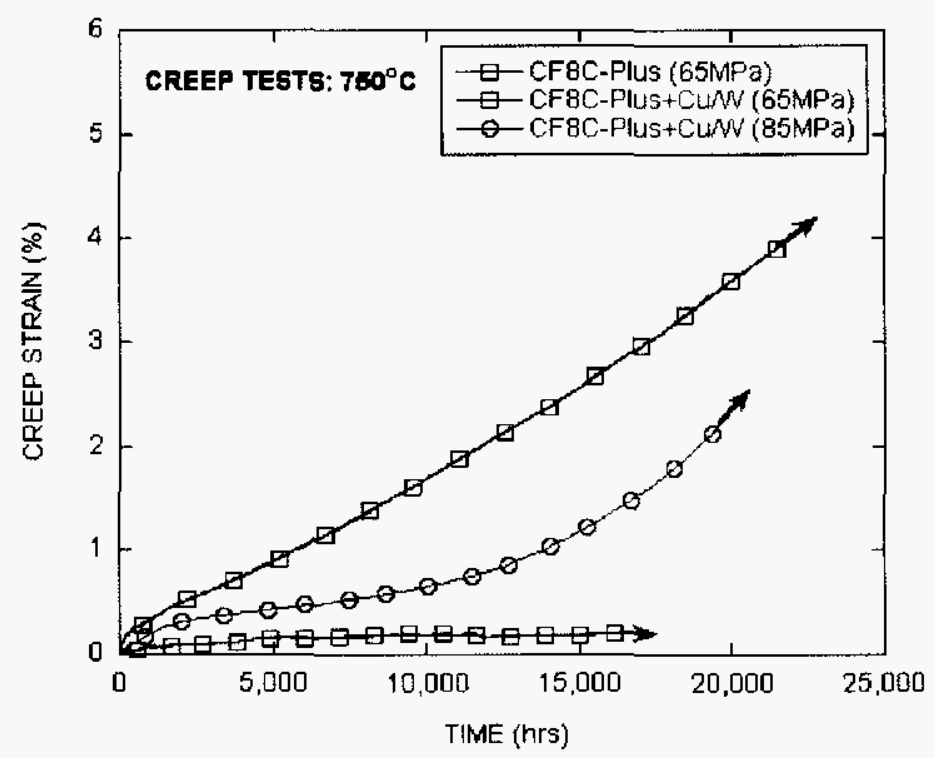

Figure 10 - Creep-strain versus time plot for creep-rupture testing in air at $750^{\circ} \mathrm{C}$ and $65-85$ $\mathrm{MPa}$ for CF8C-Plus and CF8C-Plus $\mathrm{Cu} / \mathrm{W}$ austenitic stainless steels, for specimens taken from sand-cast kiel blocks. Creep-rupture tests continue at the end of this CRADA project, with some approaching $30,000 \mathrm{~h}$. The CF8C-Plus $\mathrm{Cu} / \mathrm{W}$ clearly exhibits more creep-resistance than CF8C-Plus steel, due mainly to a very low creep-rate in the secondary-creep regime.

\section{Inventions}

Three U.S. Patent applications were made during this CRADA project, and two U.S. Patents were obtained in 2006-2007, and one is still pending. Caterpillar has also obtained foreign filings on the patents related to the CF8C-Plus steel. For more information on patent status, contact Caterpillar, Inc.

1. U.S. Patent 7,255,755, Heat and Corrosion Resistant Cast CN-12 Type Stainless Steel With Improved High Temperature Strength and Ductility, P.J. Maziasz, T. McGreevy, M.J. Pollard, C.W. Siebenaler, and R.W. Swindeman, August 14, 2007.

2. U.S. Patent 7,153,373 B2, Heat and Corrosion Resistant Cast CF8C Type Stainless Steel With Improved High Temperature Strength and Ductility, P.J. Maziasz, T. McGreevy, M.J. Pollard, C.W. Siebenaler, and R.W. Swindeman, Dec.26, 2006.

3. U.S. Patent Application was filed in July 31, 2006 by Caterpillar, Inc. for 11/495,671 "Heat and Corrosion Resistant Cast Austenitic Stainless Steel Alloy With Improved High Temperature Strength," by P.J. Maziasz, M.J. Pollard and J.P. Shingledecker. 


\section{Commercialization Possibilities}

To date, three U.S. Foundries and one U.S. gas-turbine OEM have signed trial licenses for casting CF8C-Plus steel, including MetalTek International, Stainless Foundry \& Engineering (SF\&E), and General Electric. Stainless Foundry \& Engineering was engaged by ORNL and Caterpillar in 2006 to do the critical testing (welding cast plates and measure U-bend and tensile ductility of welds) and put together a data package and apply to the ASTM A297 Committee for a new heat-resistant casting alloy grade. The application was made in May, 2007 and CF8C-Plus was given the new alloy grade designation HG10MNN; at the end of this CRADA in July, 2008, the ASTM Committee action for HG10MNN is in the final stage of the approval process. SF\&E signed a commercial license (with royalties) with Caterpillar (and ORNL by 50/50 mutual agreement) near the end of May, 2008. Caterpillar and Honeywell Turbo Technologies began collaboration on testing and evaluation of casting prototype turbocharger housings for diesel engines of CF8C-Plus steel in mid-2007, and that effort is in-progress at the end of this CRADA project.

Since about 2005, seven conference or technical journal papers about CF8C-Plus steel have been published to stimulate commercial interest. Those publications have helped to motivate Honeywell Turbo Technologies and General Electric to test and evaluate cast CF8C-Plus for their specific applications.

\section{Plans for Future Collaboration}

In late 2007, ORNL was awarded substantial funding by the DOE/EERE Technology Commercialization and Development Program for 12 months to work with Caterpillar and Honeywell Turbo Technologies to support the turbocharger housing application. At the end of this CRADA, ORNL and Honeywell have begun on a new CRADA, NFE-08-01259 entitled "Cast CF8C-Plus Stainless Steel for Turbocharger Applications," to complete the transfer of technology for this specific application.

\section{Conclusions}

The new cast austenitic stainless steel CF8C-Plus was developed and scaled up to commercial heats in about 1.5 years. CF8C-Plus steel has twice the creep-rupture strength, and much more creep ductility than standard $\mathrm{CF} 8 \mathrm{C}$ steel at $600-900^{\circ} \mathrm{C}$. CF8C-Plus steel has excellent castability, is very weldable, and requires no post-cast heat-treatments. CF8C-Plus steel is a cost-effective upgrade for SiMo cast iron and Ni-Resist austenitic cast iron, with much more performance, temperature capability, and reliability. The new $\mathrm{CF} 8 \mathrm{C}-\mathrm{Plus} \mathrm{Cu} / \mathrm{W}$ steel shows promise of even higher creep-strength at $750-850^{\circ} \mathrm{C}$. Further evaluation of new CF8C-Plus steel shows that its strength is comparable to the best commercial wrought stainless steels, including NF709, or to Ni-based superalloys such as 617, which are 5-7 times more expensive. Commercialization of CF8C-Plus steel for the CRS/DPF application on Caterpillar diesel engines has been a tremendous success. The CF8C-Plus steel is also an attractive candidate for other diesel and automotive exhaust components, such as turbocharger housings and manifolds, as well as for large turbine component applications, including steam and gas turbine casings, or for fuel cell balance of plant components. 


\section{Acknowledgements}

Particular thanks to D. Ray Johnson, Manager - Heavy Vehicle Propulsion Materials program at Oak Ridge National Laboratory, and Sidney Diamond and Jerry Gibbs, Technology Area Development Managers -Propulsion Materials, Office of Vehicle Technologies, under the Assistant Secretary for Energy Efficiency and Renewable Energy at the U.S. Department of Energy for their funding support and technical interest in this project. We, in particular, want to acknowledge the guidance, leadership, and vision of the late Dr. Sidney Diamond, a friend and mentor to us all. Thanks also to Jeff Jensen - Engineering Supervisor of Advanced Materials Technology at the Caterpillar Technical Center, and to Mort Sill - Manager of Technology Transfer, and Craig Habeger and Lou Balmer-Millar - Engineering Supervisors of Advanced Materials Technology at the Caterpillar Technical Center, for their support and encouragement. 


\section{DISTRIBUTION}

Internal Distribution

1. C. A. Blue, 4500 S, MS-6134

2. R. G. Boeman, NTRC, MS-6472

3. P. A. Carpenter, 4500 N, MS-6269

4. D. C. Christensen, 4500 N, MS-6248

5. A. G. DeTrana, $4500 \mathrm{~N}, \mathrm{MS}-6196$

6. $\quad$ E. P. George, 4500 S, MS-6115

7. R. A. Hawsey, 4500 N, MS-6186

8. D. R. Johnson, 4515, MS-6066

9. E. Lara-Curzio, 4515, MS-6069

10. P. J. Maziasz, 4500S, MS-6115

11. Office of Technical Information \& Classification, 6011, MS-6283

12. C. Porto, 4500 N, MS-6196

13. T. M. Rosseel, 4500S, MS-6161

14. K. M. Wilson, 111-B UNV, MS-6499

15. S. J. Zinkle, 4500 S, MS-6132

16. DOE-WFO, 1000, MS-6269

External Distribution

17. J. M. Aurrecoechea, Solar Turbines, Inc., 215 Centre Park Blvd, DeSoto, TX 75115

18. A. K. Battacharya, Solar Turbines, Inc., 215 Centre Park Blvd, DeSoto, TX 75115

19. P. F. Browning, Solar Turbines, Inc., Manager - Overhaul Project Management, DeSoto Overhaul Facility, 215 Centre Park Blvd, DeSoto, TX 75115

20. M. E. Frary, Boise State University, MEC 302A, Boise, ID 83725

21. Mark Geister, Caterpillar, Inc., Technical Center E, Mossville, IL 61552

22. J. L. Gibbs, Department of Energy, EE-2G, 1000 Independence Ave., S.W., FORS Building, Washington, DC 20585

23. J. A. Jensen, Catepillar, Inc., Technical Center E, Mossville, IL 61552

24. T. E. McGreevy, Caterpillar, Inc., Technical Center E, Mossville, IL 61552

25. M. J. Pollard, Caterpillar, Inc., Technical Center E, Mossville, IL 61552

26. John Shingledecker, Electric Power Research Institute, 1300 West W. T. Harris Blvd., Charlotte, NC 28262

27. C. W. Siebenaler, Caterpillar, Inc., Technical Center E, Mossville, IL 61552 